\title{
ПРЕОБРАЗУЮЩИЕ ИНВЕСТИЦИИ В ИНФРАСТРУКТУРНОМ РАЗВИТИИ МАКРОРЕГИОНА: СОЦИААЬНЫЙ АСПЕКТ
}

\begin{abstract}
Аннотауия. Предметом исследования выступает социальная инфраструктура макрорегиона. РОль инфраструктуры региона, а особенно сочиальной, в современных условиях протекающих соииально-экономических процессов неуклонно возрастает. Из вспомогательной и «обслуживающей» отрасли инфраструктура начинает выступать одним из решающих факторов повышения качества экономического роста, направленного на рост качества жизни населения в целом. В этих условиях актуализируется задача обеспечения функционирования и развития инфраструктуры и поиска таких способов ее инвестирования, которые могли бы объединить усилия различных субъектов экономической деятельности в регионах. Одним из методов является преобразующее инвестирование, обеспечивающее комплексный подход в достижении не только финансовых результатов, но также соииальных и экологических, основанных на ряде приниипов. Џель статьн. Цель статьи заключается в исследовании вопросов обеспечения развития инфраструктуры как фактора повышения качества жизни населения на основе преобразующих инвестичий. В качестве объекта исследования выступают субъекты Уральско-Сибирского макрорегиона, анализ инфраструктуры которых позволяет выявить существующие тенденции ее развития. Методы исследования. В работе использованы общенаучные методы анализа и синтеза. При обработке массива статистической информации использован системный подход, позволяющий выявить основные тендениии развития инфраструктуры, выявить особенности преобразующих инвестииий. Результаты работы.

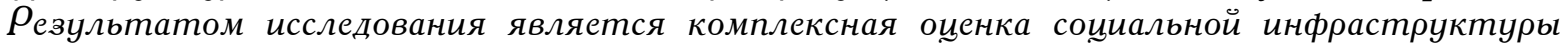
макрорегиона на основе анализа индекса развития инфраструктуры, а также анализа показателей индекса развития человека и сочиального прогресса. Также обоснована необходимость развития преобразующего инвестирования, выявлены особенности данной формы инвестирования в контексте финансирования объектов соииальной сферы. Об-

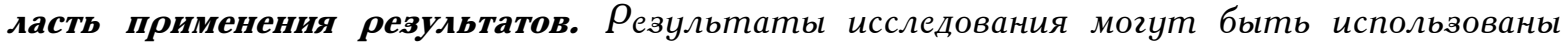
для сопоставления инвестиционных процессов в экономическом пространстве региона и особенностей реализащии преобразующих инвестищий. Также результаты могут быть использованы при составлении программ регионального развития в области преобразующиих (impact) инвестищий. Выводы. В статье сделан вывод об усиливающейся роли преобразующих инвестищий при их реализащии в развитии общей и соџиальной инфраструктуры регионов с иелью повышения ее способности удовлетворять потребности человека. Ключевые слова: преобразующие инвестищии, социальная инфраструктура региона, индекс развития инфраструктуры, макрорегион, развитие, качество жизни.
\end{abstract}

\author{
KVON GULNARA MAGSUMOVNA \\ $\rho_{h .}$., associate $\rho_{\text {rofessor, }} \rho_{\text {rofessor of regional and }}$ \\ municipal Economics and management \\ Ural state University of Economics (USUE), \\ Yekaterinburg, Russia, e-mail: Sung2002@mail.ru
}

\section{TRANSFORMATIVE INVESTMENT IN INFRASTRUCTURE DEVELOPMENT MACRO-REGION: THE SOCIAL ASPECT}

Abstract. The subject of the study is the social infrastructure of the macroregion. The role of the region's infrastructure, especially social infrastructure, is steadily increasing in the current con- 
ditions of ongoing socio-economic processes. From a supporting and "servicing" industry, infrastructure is beginning to act as one of the decisive factors for improving the quality of economic growth aimed at improving the quality of life of the population as a whole. In these conditions, the task of ensuring the functioning and development of infrastructure and finding ways to invest it that could unite the efforts of various economic entities in the regions is becoming more urgent. One of the methods is transformative investment, which provides an integrated approach to achieving not only financial results, but also social and environmental, based on a number of principles. Purpose of article. The purpose of the article is to study the issues of ensuring infrastructure development as a factor in improving the quality of life of the population on the basis of transformative investments. The object of research is the subjects of the Ural-Siberian macroregion, the analysis of which infrastructure allows us to identify existing trends in its development. Method of research. The paper uses General scientific methods of analysis and synthesis. When processing an array of statistical information, a systematic approach is used to identify the main trends in infrastructure development and identify the features of transformative investments. $\boldsymbol{R} \boldsymbol{e}$ sult of work. The result of the study is a comprehensive assessment of the social infrastructure of the macroregion based on the analysis of the infrastructure development index, as well as the analysis of indicators of the human development index and social progress. The necessity of developing transformative investment is also justified, and the features of this form of investment in the context of financing social facilities are identified. Scope of the results. The results of the research can be used to compare investment processes in the economic space of the region and the specifics of implementing transformative investments. The results can also be used in the preparation of regional development programs in the field of transformative (impact) investments. Conclusions. The article concludes about the increasing role of transformative investments in their implementation in the development of the General and social infrastructure of regions in order to increase its ability to meet human needs.

Keywords: transformative investments, social infrastructure of the region, infrastructure development index, macroregion, development, quality of life.

Введение. Социально-экономическое развитие любой территории как результат реализации эффективной региональной политики представляет собой сложный многомерный процесс, предопределяющий необходимость эффективного использования всех ресурсов территории, развития механизмов государственно-частного партнерства, соблюдения интересов населения в получении качественных общественных услуг, учет культурной, духовной и национальной составляющей территории, уклада жизни. Немаловажную роль в данном процессе играет ее инфраструктура, которая характеризует общие условия эффективного функционирования и развития любого региона. Необходимо отметить, что инфраструктура сама по себе не является фактором, который способствовал бы повышению инвестиционной привлекательности и конкурентоспособности региона, но ее несоответствие потребностям регионального развития сказывается отрицательно.

Важность инфраструктурного обеспечения социально-экономического развития территорий обозначена в Стратегии пространственного развития [18] как одного из ключевых факторов, определяющих конкурентоспособность региона. Макроэкономический подход к трактовке инфраструктуры как экономической категории включает, помимо материальной и операционной составляющих, также рыночную и институциональную [20].

Согласно работе Кэмпбелла Р Макконенлла и Стэнли Л. Брю [9], под инфраструктурой следует понимать «...капитальные сооружения, использование которых гражданами и фирмами обычно обеспечивается государством (автомагистрали, мосты, городские транспортные системы, водоочистные сооружения, муниципальные системы водоснабжения, аэропорты)...». В работе А. А. Говорина [3] инфраструктура - это «...объективно сложившаяся в результате общественного разделения труда система общих условий обеспечения общественного воспроизводства ..., представляющая совокупность рациональных технико-технологических, организационно-экономических, информационных, социальных и других взаимосвязей по эффективному обслуживанию функционирования структурообразующих отраслей и жизнеобеспечения населения».

Важность инфраструктуры обозначена и в статьях П. Розенштейна-Родана, автора теории 
«большого толчка», который в своих работах [23], [24] говорил о «социальном накладном капитале», включающем такие отрасли промышленности, как энергетика, транспорт, коммуникации и т. д., которые должны предшествовать более быстрым, непосредственно производительным инвестициям и которые составляют основу или «инфраструктуру». Розенштейн объяснял необходимость первоочередного инвестирования в инфраструктуру, мобилизации инвестиционных средств, которые и являются своеобразным «толчком», однако необходимая сумма инвестиций различается в зависимости от уровня развития стран.

Поэтому, говоря об инфраструктуре, можно выделить два подхода при определении ее экономической сущности: отраслевой (как совокупность отраслей, обеспечивающих общие условия воспроизводства) и функциональный (как систему общих условий обеспечения общественного воспроизводства, представляющую совокупность взаимосвязей элементов социальноэкономической системы) [15].

Методы исследования. Методология исследования предусматривает выбор алгоритма и методов исследования, подбор исходных данных, изучение нормативной базы исследования, анализ публикационной активности в изучаемом вопросе, подбор базы исследования, формирование выводов. В качестве источников информации использованы данные статистической отчетности по субъектам РФ, различные индикаторы, результаты оценки рейтингов независимых рейтинговых агентств и аналитических компаний и др. В качестве методов исследования в данной работе приняты методы сбора и обобщения данных, анализа и синтеза, при этом обработка массива статистической и прочей информации основывалась на системном подходе, результаты исследования представлены в табличной и графической формах.

Оценка инфраструктуры по отраслевому признаку в разрезе регионов и в целом по Российской Федерации проводится аналитическим подразделением группы компаний InfraOne, которые с 2018 года проводят расчеты региональной инфраструктуры на основе интегрального показателя «индекс развития». Расчеты проводятся по 10-балльной шкале по каждому региону в разрезе таких отраслей инфраструктуры, как транспортная, энергетическая, социальная, коммунальная и телекоммуникационная [5].

Ранее автором была проведена комплексная оценка инвестиционной среды макрорегиона и входящих в него субъектов (на примере Уральского макрорегиона), позволяющая определить их инвестиционный потенциал с учетом стратегических приоритетов инвестиционной деятельности [6].

В данной работе автор считает необходимым рассмотреть вопросы влияния инфраструктуры на развитие субъектов Уральско-Сибирского макрорегиона, сделав акцент на социальную инфраструктуру и связав данный процесс с относительно новым понятием «преобразующие инвестиции».

На рис. 1 представлены интегральный индекс РФ, Уральского-Сибирского макрорегиона ${ }^{1}$ и индексы по регионам, входящим в данный макрорегион.

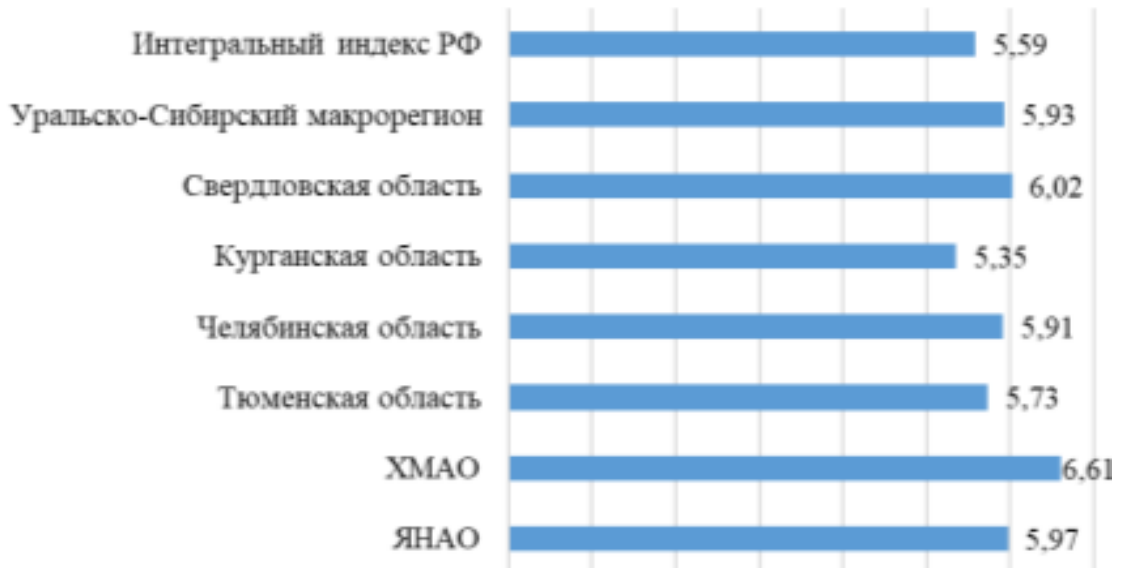

Pис. 1. Интегральные индексы инфраструктуры по данным 2019 года по субъектам Уральского-Сибирского макрорегиона [5].

\footnotetext{
${ }^{1}$ Компонентный состав регионов представлен согласно вышеуказанной Стратегии пространственного развития.
} 
Квон Г.М.

ПРЕОБРАЗУЮЦИЕ ИНВЕСТИЦИИ В ИНФРАСТРУКТУРНОМ РАЗВИТИИ МАКРОРЕГИОНА: СОЦИАЛЬНЫЙ АСПЕКТ

Интегральный индекс макрорегиона превышает значения интегрального индекса в целом по РФ. Лидерами в развитии инфраструктуры по оценке InfraOne являются ХантыМансийский автономный округ и Свердловская область (индексы 6,61 и 6,02 соответственно).

Рассмотрим результаты оценки инфраструктуры по каждому субъекту макрорегиона в разрезе отдельных отраслей (таблица 1).

Индексы развития инфраструктуры по данным 2019 года по субъектам Уральского-Сибирского макрорегиона в разрезе отраслей

\begin{tabular}{|c|c|c|c|c|c|c|c|c|}
\hline \multirow[b]{2}{*}{$\begin{array}{c}\text { Индекс } \\
\text { инфраструктуры }\end{array}$} & \multirow{2}{*}{$\begin{array}{c}\text { РФ } \\
\text { Интеграль- } \\
\text { ный индекс } \\
\text { РФ }\end{array}$} & \multirow{2}{*}{$\begin{array}{c}\text { Уральско- } \\
\text { Сибирский } \\
\text { макрорегион }\end{array}$} & \multicolumn{6}{|c|}{ В том числе по субъектам } \\
\hline & & & $\begin{array}{c}\text { Свердлов- } \\
\text { ская область }\end{array}$ & $\begin{array}{c}\text { Курган- } \\
\text { ская об- } \\
\text { ласть }\end{array}$ & $\begin{array}{c}\text { Челябин- } \\
\text { ская об- } \\
\text { ласть }\end{array}$ & $\begin{array}{c}\text { Тюмен- } \\
\text { ская об- } \\
\text { ласть }\end{array}$ & XMAO & ЯНАО \\
\hline $\begin{array}{l}\text { Интегральный } \\
\text { индекс, }\end{array}$ & 5,59 & 5,93 & 6,02 & 5,35 & 5,91 & 5,73 & 6,61 & 5,97 \\
\hline $\begin{array}{l}\text { в том числе } \\
\text { инфраструктуры: }\end{array}$ & & & & & & & & \\
\hline транспортной & 3,21 & 3,54 & 3,11 & 2,89 & 3,61 & 3,29 & 4,06 & 4,30 \\
\hline энергетической & 5,02 & 6,07 & 6,68 & 4,65 & 5,75 & 5,32 & 8,73 & 5,31 \\
\hline социальной & 5,42 & 5,34 & 6,42 & 5,23 & 5,24 & 4,69 & 4,75 & 5,28 \\
\hline коммуникационной & 6,91 & 7,09 & 7,09 & 6,15 & 7,32 & 6,86 & 7,40 & 7,72 \\
\hline $\begin{array}{l}\text { телекоммуникаци- } \\
\text { онной }\end{array}$ & 6,45 & 6,81 & 6,96 & 5,86 & 6,91 & 7,12 & 7,00 & 7,02 \\
\hline
\end{tabular}

Данные, представленные в таблице 1 , свидетельствуют о достаточно сильных позициях макрорегиона при сравнении со среднероссийскими значениями, все отраслевые индексы по макрорегиону (кроме социального) их превышают. Рассмотрим более подробно социальную инфраструктуру макрорегиона, которая призвана гарантировать соответствующий уровень и качество жизни населения, удовлетворение его потребностей, а также обеспечивать воспроизводство трудовых ресурсов для экономики страны.

Социальную инфраструктуру образуют сферы жилищно-коммунального хозяйства, здравоохранения, спорта, общественного питания, бытового обслуживания, образования, культуры, науки и т. д. В отдельных случаях жилищно-коммунальное хозяйство выделяется в инфраструктуру жизнеобеспечения.

В оценке Группы компаний InfraOne [5] данный отраслевой индекс включает показатели обеспеченности региона спортивными объектами, детскими садами, местами в больницах, вузах и ссузах (в расчете на душу населения), заполненность общеобразовательных школ и общую ветхость фонда. В дальнейшем эта оценка, согласно аналитическому обзору компании [1], будет дополняться, т. к. в данный рейтинг не вошли показатели, учитывающие учреждения культуры, наличие инфраструктуры отдыха и наличие индустрии развлечений в виду отсутствия статистических данных по ним.

О динамике многих социальных процессов, которые происходят во многих странах, а также в РФ и ее регионах, может свидетельствовать ряд индикаторов, которые позволяют отразить достижения в процессах человеческого развития. К ним можно отнести индекс человеческого развития (Human Development Index - HDI), индекс социального прогресса (Social Progress Index - SPI) и др. Индекс человеческого развития ${ }^{2}$ представляет собой составной статистический показатель, который направлен на смещение фокуса экономического развития на социальную политику и развитие социальной инфраструктуры, которая, в свою очередь, должна быть ориентирована на повышение качества и уровня жизни. Индекс направлен на измерение здоровья и долголетия человека, его знаний, а также достойного уровня жизни. Согласно докладу ООН [11], концепция человеческого развития направлена на расширение бо-

\footnotetext{
2 Данный индекс до 2013 года назывался индексом развития человеческого потенциала.
} 
гатства человеческой жизни.

Согласно методологии ООН, все страны ранжируются в зависимости от их вхождения в одну из 4 групп:

1. HDI > 0,8 характеризует очень высокий уровень человеческого развития.

2. $0,7<\mathrm{HDI}<0,8-$ высокий уровень человеческого развития.

3. $0,55<\mathrm{HDI}<0,7-$ средний уровень человеческого развития.

4. HDI $<0,55$ - низкий уровень человеческого развития.

На рис. 2 представим результаты оценки HDI, составленные по данным аналитического центра при Правительстве РФ [12] и [13] за 2000-2017 годы.

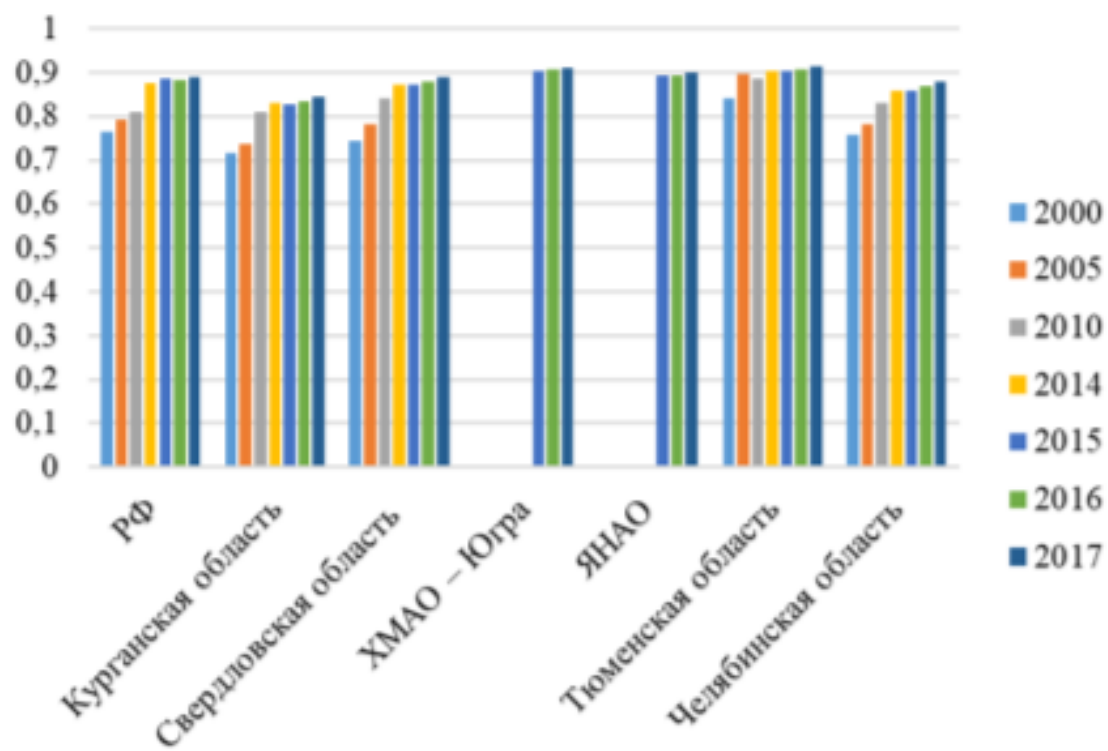

Pис. 2. Динамика индекса человеческого развития (HDI) по субъектам Уральско-Сибирского макрорегиона за 2005-2017 годыз ${ }^{3}$.

Результаты, представленные на графике, показывают положительную динамику индекса человеческого развития по макрорегиону, при этом все субъекты (кроме Челябинской и Курганской областей) имеют значения, превышающие средние значения индекса по РФ.

Данные за 2017 год ${ }^{4}$, согласно выше представленной группировке, позволяют отнести регионы к следующим группам развития (таблица 2).

Уровни развития регионов Уральско-Сибирского

Таблииа 2 макрорегиона по индексу (HDI) за 2017 год

\begin{tabular}{|l|c|c|}
\hline \multicolumn{1}{|c|}{ Субъекты } & Значение индекса & Уровень развития \\
\hline РФ & 0,89 & развитый \\
\hline Уральско-Сибирский макрорегион & 0,912 & высокоразвитый \\
\hline В том числе: & 0,843 & среднеразвитый \\
\hline Курганская область & 0,889 & развитый \\
\hline Свердловская область & 0,911 & высокоразвитый \\
\hline ХМАО - Югра & 0,901 & высокоразвитый \\
\hline ЯНАО & 0,914 & развитый \\
\hline Тюменская область & 0,879 & развитый \\
\hline Челябинская область &
\end{tabular}

$3 \longdiv { \text { Данные по ХМАО-Югра и ЯНАО учитываются в отчетности с } 2 0 1 5 \text { года } }$

${ }^{4}$ Аналитика ограничена 2017 годом, данные за 2018 год на момент написания статьи отсутствуют. 
Уральско-Сибирский макрорегион в целом можно отнести к высокоразвитому, такую же характеристику имеют ХМАО - ЮГРА и ЯНАО. Остальные регионы (кроме Курганской области), согласно методологии $\mathrm{OOH}$, попадают в группу развитых регионов, Курганская область при этом является среднеразвитым регионом.

Взаимосвязь качества жизни и устойчивого развития представлена в работе П. Леочи, доказывающим важность качества жизни «для планирования деятельности и создания будущих производств на определенных территориях» [8], который в своей работе обобщил существующие методы оценки социальных индикаторов, необходимых для контроля «социальной системы, измерения изменений и выработки необходимых мер для изменения курса социальных перемен» [21].

Индекс социального прогресса (SPI), разработанный в 2013 году Майклом Портером, также является индексом, характеризующим социальное развитие и позволяющим оценить достижения социальной политики в контексте общественного благополучия. Индекс рассчитывается на основе большого количества социальных и экологических параметров (свыше 50), которые группируются по трем блокам: основные потребности человека, возможности его развития и основы благополучия. Результаты оценки индекса социального прогресса по России представлены в таблице 3.

Индекс социального прогресса (SPI) по РФ за 2014-2018 годы [16]

\begin{tabular}{|l|c|c|c|c|c|}
\hline Показатели & 2014 & 2015 & 2016 & 2017 & 2018 \\
\hline Значение индекса & 82,5 & 82,77 & 83,00 & 83,4 & 83,89 \\
\hline Рейтинг/место РФ (из 149 стран) & 66 & 66 & 64 & 64 & 66 \\
\hline
\end{tabular}

Индекс находится в диапазоне от 0 до 100 единиц. Максимальное значение при сравнении стран характеризует их наибольшую устойчивость. Россия по оценке индекса входит в первую половину стран. На первом месте, по данным 2018 года, находится Норвегия (индекс - 90,26), на последнем - Центральноафриканская республика (индекс - 26,01).

Адаптированный индекс социального прогресса на примере регионов Уральского федерального округа, совпадающего по составу субъектов в соответствии со стратегией пространственного развития с составом Уральско-Сибирского макрорегиона, представлен в работе Е. В. Попова и К. А. Семячкова [12]. Авторами с целью адаптации международного аналога (индекса SPI) к российским условиям проведена оценка уровня социального развития регионов по 43 индикаторам, объединенным в вышеуказанные три блока. Ряд показателей в оценке отсутствует (защита права граждан и др.) в виду того, что они представляют определенную сложность при их адаптации на региональный уровень. В таблице 4 представлены результаты расчета авторов [12].

\section{Таблица 4}

\section{Оценка индекса социального прогресса за 2017 год (SPI) по субъектам Уральско-Сибирского макрорегиона [12]}

\begin{tabular}{|c|c|c|c|c|}
\hline \multirow{2}{*}{$\begin{array}{l}\text { Субъекты УрФО (Уральско- } \\
\text { Сибирского макрорегиона) }\end{array}$} & \multirow{2}{*}{$\begin{array}{l}\text { Суммарное зна- } \\
\text { чение индекса }\end{array}$} & \multicolumn{3}{|c|}{ В том числе по группам (блокам): } \\
\hline & & Возможности развития & Основы благополучия & $\begin{array}{c}\text { Основные } \\
\text { потребности }\end{array}$ \\
\hline Курганская область & 0,89 & 0,17 & 0,42 & 0,36 \\
\hline Свердловская область & 2,05 & 0,84 & 0,67 & 0,53 \\
\hline Тюменская область & 1,32 & 0,46 & 0,53 & 0,32 \\
\hline Челябинская область & 1,23 & 0,51 & 0,43 & 0,29 \\
\hline
\end{tabular}


Лидером, по оценке авторов ,является Свердловская область, которая сбалансирована по всем группам показателей.

Результаты. Развитие социальной сферы с целью достижения устойчивого развития регионов актуализирует вопросы повышения качества жизни как «желаемого результата политики и социальных программ» [25]. Устойчивое развитие как процесс не только экономических, но и социальных изменений предполагает согласованное взаимодействие научно-технического развития, использование природных ресурсов, обеспечение развития личности и др. факторов. Также оно предполагает расширение инвестиционных процессов с целью удовлетворения человеческих потребностей и укрепления будущего потенциала. В этой связи с концепцией устойчивого развития (она содержит 17 целей), принятой ООН в 2015 году, [13], часто связывают социальное инвестирование, импакт-инвестирование, социально ответственное или преобразующее инвестирование. В данной статье вышеупомянутые категории будем принимать за синонимы, хотя при более глубоком рассмотрении следует понимать, что каждая дефиниция имеет свои особенности. Концепция преобразующего инвестирования стремится найти баланс между достижением социально-экономических результатов и социальных или экологических преобразований общества для будущего всего человечества. Глобальный договор $(\mathrm{OOH})^{5}$ содержит призыв к компаниям вести свою деятельность со всеобщими принципами в области прав человека, охраны окружающей среды и т. д., т. е. направлен на международное введение принципов социально-экономической и экологической ответственности.

В современных условиях функционирования мировой экономической системы меняется роль инфраструктуры, которая из «обслуживающей» вспомогательной сферы становится одной из ведущих отраслей, способствующих приведению многих стран к устойчивому росту [19].

Инвестирование в инфраструктуру характеризуется низкой нормой прибыли, длительными сроками окупаемости, зачастую трудно поддается экономической оценке. При этом данные инвестиции являются достаточно капиталоемкими. В виду вышеперечисленных причин отрасли инфраструктуры не являлись привлекательными для частного бизнеса и, как правило, финансировались за счет государственных расходов. Усиливающаяся дифференциация регионов по уровню их социально-экономического развития [2], необходимость решать социально значимые проблемы (загрязнение окружающей среды, сокращение вредных выбросов, обеспечение ресурсосбережения, сокращение неравенства, снижение бедности и др.) сместили акцент на инфраструктурные проекты. Модернизация инфраструктуры, финансирование инфраструктурных проектов, реализация которых обеспечивает мультипликационный эффект (создаются новые рабочие места, сокращаются издержки в сопряженных отраслях, развиваются новые технологии и т. д.), формирование новой парадигмы мышления правительственных органов и частного бизнеса, филантропов повысили привлекательность инвестирования в инфраструктуру, оказание социальных услуг.

Понятие преобразующих инвестиций («impact investment») связывают с деятельностью Фонда Рокфеллера в 2007-2008 годах и не ассоциируют с благотворительностью и филантропией. Импакт-инвестирование нацелено на получение комбинированной ценности (органичной экологической, социальной и экономической результативности). Предполагается, что ценность будет получена из-за использования новых инвестиционных инструментов для решения социальных и экологических проблем, при этом деятельность по импакт-инвестированию планируется и прогнозируется. Основными постулатами концепции фонда выступили три составляющие TBL - планета, люди и прибыль. При этом получение экономического результата сопровождается получением социального и/или экологического результата, согласно социальной справедливости. Основные участники преобразующего инвестирования - это инвестор, посредник (который определяет критерии проектов) и получатель.

Преобразующие инвестиции называют ответственными и инвестициями воздействия (влияния) в виду того, что при инвестировании соблюдаются этические принципы (многие фонды, например фонд Vanguard FTSE Social Index, Parnassus Endeavor и Parnassus Mid-Cap, исключили из объектов инвестирования проекты, которые причастны к производству атомной энергетики, военной сфере, производству и продаже алкоголя, табачных изделий). Основные направления преобразующего инвестирования: доступное здравоохранение, финансирование в образо-

${ }_{5}^{5}$ Глобальный договор - инициатива ООН (Всемирный экономический форум, 1999 год). 
вание, поддержка сельскохозяйственного производства, решение экологических проблем, т. е. те направления, которые в результате способствуют развитию инфраструктуры России и ее регионов. Объем рынка преобразующих инвестиций постоянно растет, создана организация (платформа) преобразующего инвестирования GIIN (Global Impact Investing Network). Россия в GIIN представлена фондом «Наше будущее», который входит в рабочую группу не только по России, но и по Восточной Европе [16]. На начало 2019 года объем мирового рынка преобразующих импакт-инвестиций составляет 502 млрд долларов, в котором участвуют 1340 организаций, при этом годовой рост рынка составляет $29 \%$ [17].

Основная направленность преобразующих инвестиций - соответствие целям устойчивого развития ООН [13], таким как борьба с бедностью, развитие инфраструктуры, обеспечение «социальной справедливости» и т. д., т. е. общий посыл инвестиций - оказание позитивного воздействия на окружающий мир. Необходимо отметить, что компании, осуществляющие преобразующие инвестиции, добровольно используют принципы ESG (Environmental, Social, Governance), под которыми понимается учет в своей деятельности экологических (Е) и социальных (S) факторов, а также факторов корпоративного управления (G). Использование этих принципов сближает инвестиционную политику компаний с ожиданиями общества [7].

Рассмотрим ситуацию с инвестированием в социальную инфраструктуру макрорегиона, использовав данные официальной статистики по такому показателю, как инвестиции в основной капитал [11], представив динамику общих инвестиций и инвестиций в социальную сферу за 2005-2018 годы (рис. 3). Социальная сфера в данном исследовании ограничена такими показателями, как инвестиции в образование, здравоохранение и социальную политику.

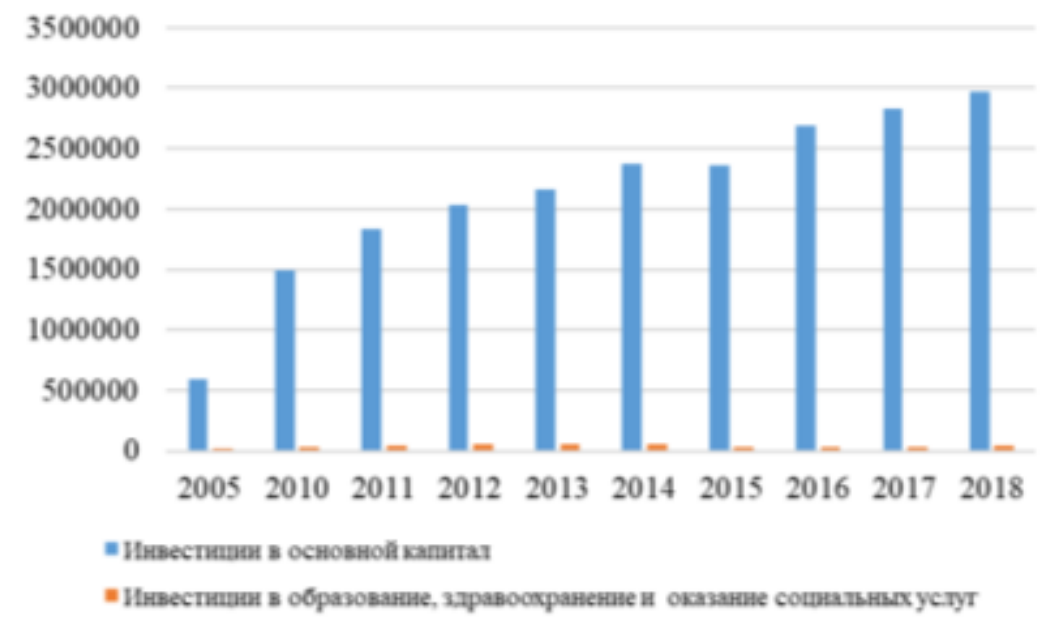

Pис. 3. Динамика инвестиций в основной капитал по Уральско-Сибирскому макрорегиону за 2005-2018 годы, млн руб.

Несмотря на то, что общая сумма инвестиций по годам имеет положительную тенденцию (незначительное снижение наблюдалось в 2015 году как последствие негативных кризисных явлений 2014 года), в целом ситуация по макрорегиону является позитивной. Однако инвестирование в социальную сферу с 2014 года снижается как в абсолютной сумме инвестиций, так и в относительном исчислении (сумма «социальных» инвестиций, по данным 2018 года, составляет всего 1,3 \%). Динамика инвестиций по субъектам макрорегиона, составленная по данным [11], представлена на рис. 4.

Положительная динамика инвестиций за последние два года (после снижения их суммы в 2014 году) наблюдается у всех регионов, при этом Челябинская и Тюменская области превысили данные 2014 года.

Необходимо отметить, что представленные инвестиции в социальную сферу нельзя считать в полном объеме преобразующими, на данный момент не существует полной статистки по данному виду инвестиций, так как не все организации предъявляют публично сведения о том, какие суммы ими вкладываются в решение социальных проблем. К тому же существуют определенные трудности в определении социального эффекта, который, как правило, предусматривает отдачу в будущие периоды и зачастую проявляется опосредовано, не напрямую. 


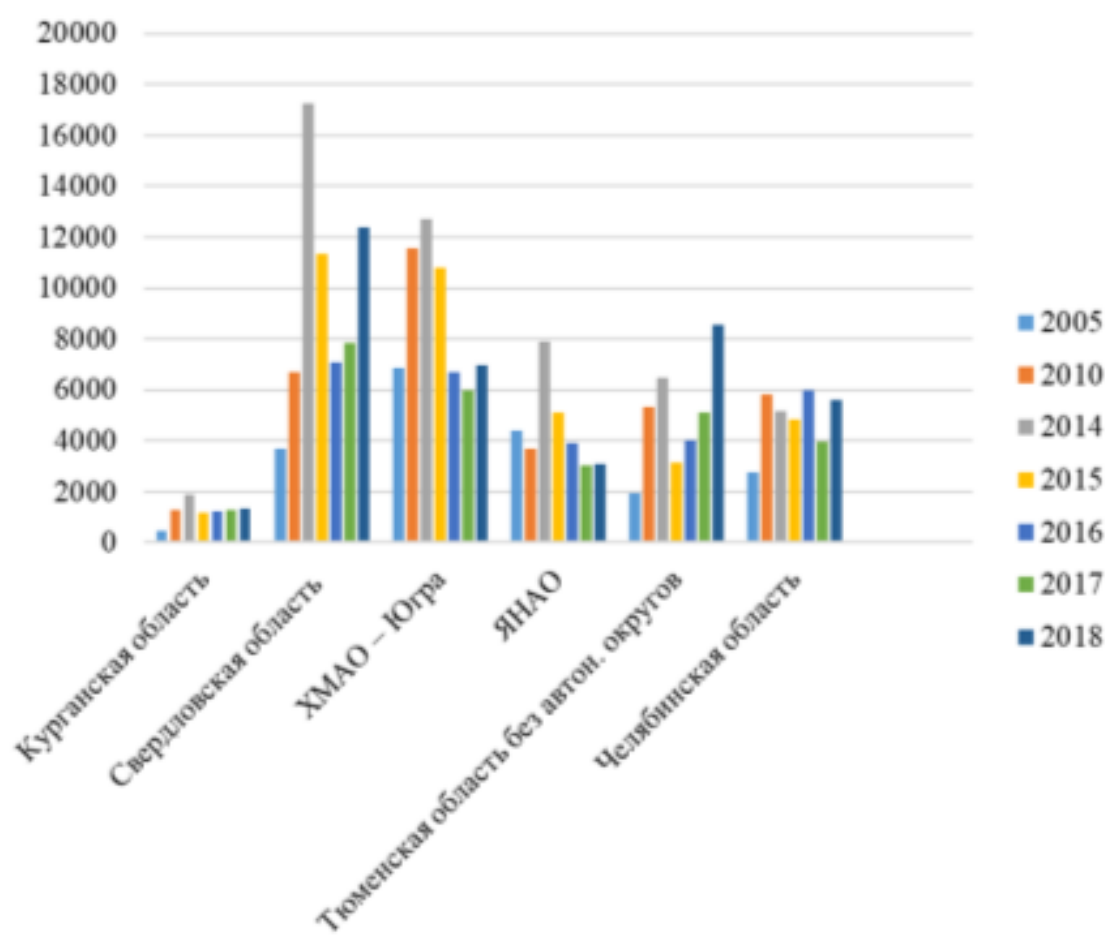

Pис. 4. Динамика инвестиций в основной капитал соииальной сферы по субъектам Уральско-Сибирского макрорегиона за 2005-2018 годы.

Выводы. Развитие социальной инфраструктуры регионов России требует использования комплексного подхода к решению взаимосвязанных проблем в различных ее отраслях. Реализация проектов с целью преодоления социального неравенства, снижения социальной напряженности, повышения качества жизни населения приводит к необходимости использования новых подходов к инвестированию, отличающихся от традиционных пониманием руководителями компаний ответственности за окружающую среду, социальную сферу, соблюдением прав работников. Достоинством преобразующих инвестиций является достижение ими не только социального эффекта, но и коммерческого, в результате их реализации создается стоимость, которая содержит экономические, социальные и экологические составляющие.

Литература

1. Аналитический обзор «Инфраструктура России: индекс развития 2019» / InfraONE Research. Исследовательская группа инвестиционной компании InfraONE. [Электронный ресурс]. Режим доступа: https://infraone.ru/sites/default/files/analitika/2019/

index_razvitiia infrastruktury_rossii_2019 infraone research.pdf?index_id, свободный. - Загл. с экрана.

2. Анймица Е. Г. Региональное управление [Текст̄]: курс лекций / Е. Г. Анимица; Федер. агентство по образованию, Урал. гос. экон. ун-т. - Екатеринбург : Изд-во Урал. гос. экон. ун-та. - 2010. $-340 \mathrm{c}$.

3. Говорин А. А. Инфраструктура современного предпринимательства: проблемь теории и практики. - М.: Финстатинформ, 1999. - 174 с.

4. Доклад о человеческом развитии в Российской Федераџии за 2018 год / под ред. С. Н. Бобылева и Л. М. Григорьева. - М.: Аналитический иентр при Правительстве Российской Федераџии, 2018. - 172 c. [Электронный ресурс]. Режим доступа: https://ac.gov.ru/files/publication/a/19663.pdf, свободный. - Загл. с экрана.

5.Индекс развития инфраструктуры России (2019). [Электронный ресурс]. Режим доступа: https:// infraone-research.ru/index id/2019, свободный. - Загл. с экрана.

6. Квон Г. М. Региональные аспекты развития инвестиционного потенциала уральского макрорегиона // Региональные проблемы преобразования экономики. - 2019. - № 9 (107). - С. 51-60.

7. Концепция организаџии в России методологической системы по развитию зеленых финансовых инструментов и проектов ответственного инвестирования. [Электронный ресурс]. Режим доступа: https://cbr.ru/Content/Document/File/84163/press_04102019.pdf, свободньии. - Загл. с экрана.

8. Леочи П. Качество жизни и устойчивое развитие // Экономические науки. - 2012. - № 5(90). - C. 4145 .

9. Макконнелл, Кэмпбелл Р. Экономикс [Текст]: принщипы, проблемы и политика: [в 2 т.: пер. с англ. 11-го изд.] / Кэмпбелл Р. Макконелл, Стэнли Л. Брю. - Москва: Республика, 1993. - 27 см. - Т. 2. 1993. - 400 с.: ил. 
10. Особенности развития человеческого капитала в субъектах Российской Федерации. Аналитический центр при Правительстве Российской Федерации / 11.06.2019, Москва. [Электронный ресурс]. Режим доcтуna: https://ac.gov.ru/files/content/22461/3-grigorev-pdf.pdf, свободный. - Загл. с экрана.

11. Официальная статистика. [Электронньй ресурс]. Режим доступа: https://www.gks.ru/ investment_nonfinancial, свободный. - Загл. с экрана.

12. Попов Е. В., Семячков К. А. Методология оценки соччиального развития регионов // Проблемы развития территории. - 2018. - № 6 (98). -C. 119-130. DOI: 10.15838/ptd.2018.6.98.8 Popov E. V., Semyachkov K. A. Method to Evaluate Social Development of Regions. Problems of Territory's development, 2018. No. 6 (98). P. 119-130.

13. Резолючия Генеральной Ассамблеей ООН «Преобразование намего мира: Повестка дня в области устойчивого развития на период до 2030 года». Принята 25 сентября 2015 года/ Резолюиия, принятая Генеральной Ассамблеей. [Электронный ресурс]. Режим доступа: https://undocs.org/ru/A/RES/70/1, cвободный. - Загл. с экрана.

14. Рейтинг стран мира по уровню сочиального прогресса. [Электронный ресурс]. Режим доступа: https://www.socialprogress.org/?tab=2\&code=NOR, http://www.socialprogressimperative.org, свободный. Загл. с экрана.

15.Рыжаков Е. Д. Методология формирования системы инфраструктурного обеспечения предпринимательской деятельности в регионах России // Экономические науки. - 2012. - № 96. - С. 74-77.

16. Сайт «Ассоциации импакт-инвесторов». [Электронный ресурс]. Режим доступа: http://impactinvestor.org/, свободный. - Загл. с экрана.

17. Сайт «Новый бизнес: социальное предпринимательство». [Электронный ресурс]. Режим доступа: http://nb-forum.ru/useful/social_investing/10-factov-o-preobrazueshem-investirovanii, свободньй. - Загл. с экрана.

18.Стратегия пространственного развития Российской Федераичи на период до 2025 года (2019), утверждена распоряжением Правительства РФ 13 февраля 2019 2. № 207-р. [Электронный ресурс]. Режим достуna: http://static.government.ru/media/files/UVAlqUtT08o60RktoOXl22JjAe7irNxc.pdf, cвободный. - Загл. с экрана.

19. Тимонина И. Л. Государственно-частное партнерство и «преобразующие» инвестищии в сфере социальной инфраструктуры: опыт Японии / И. Л. Тимонина // Восток. Афро-азиатские общества: история и современность. - 2016. - № 1. - С.143-159.

20. Юденко М. Н., Михайлов. М. В. Экономическая сущность инфраструктуры и ее особенности в строительстве // Вестник Российского университета дружбы народов. Серия: Экономика. - 2013. № 1. - C. 123-130.

21. K. Land. "Social Indicators», in «Encyclopedia of Sociology», MacRae, 1992, pag. 1844-1850; Revised Edition by E.F. Borgatta and R. V. Montgomery, "Encyclopedia of Sociology», Mcmillan, New York, 2000. W. Ogburn, "Recent Social Trends in the United States», pubblicato nel.

22. Overview Human Development Report 2019. Beyond income, beyond averages, beyond today: Inequalities in human development in the 21st century// Published for the United Nations Development Programme (UNDP). [An electronic resource]. Access mode: https://nonews.co/wp-content/uploads/2019/12/hdr2019.pdf, free. Heading from the screen.

23. Rosenstein-Rodan Notes on the Theory of the Big Push // Economic Development for Latin America/eds. Ellis. -1961 .

24. Rosenstein-Rodan. Problems of Industrialisation of Eastern and South-Eastern Europe // The Economic Journal. Vol. 53. No. 210/211. - 1943.

25. Schnessler K. F., Fisher G. A. Quality of Life Research and Sociology // Annual Review of Sociology.1985. Vol. 11. P. $129-149$.

\section{References:}

1. Analiticheskij obzor «Infrastruktura Rossii: indeks razvitiya 2019» / InfraONE Research. Issledovatel'skaya gruppa investicionnoj kompanii InfraONE. [Elektronnyj resurs]. Rezhim dostupa: https://infraone.ru/sites/ default/files/analitika/2019/index_razvitiia_infrastruktury_rossii_2019_infraone_research.pdf?index_id, svobodnyj. - Zagl. s ekrana.

2. Animica E. G. Regional'noe upravlenie [Tekst]: kurs lekcij / E. G. Animica; Feder. agentstvo po obrazovaniyu, Ural. gos. ekon. un-t. - Ekaterinburg : Izd-vo Ural. gos. ekon. un-ta. - 2010. - 340 s.

3. Govorin A. A. Infrastruktura sovremennogo predprinimatel'stva: problemy teorii $i$ praktiki. - M.: Finstatinform, 1999. - 174 s.

4. Doklad o chelovecheskom razvitii v Rossijskoj Federacii za 2018 god / pod red. S. N. Bobyleva i L. M. Grigor'eva. - M.: Analiticheskij centr pri Pravitel'stve Rossijskoj Federacii, 2018. - 172 s. [Elektronnyj resurs]. Rezhim dostupa: https://ac.gov.ru/files/publication/a/19663.pdf, svobodnyj. - Zagl. s ekrana.

5.Indeks razvitiya infrastruktury Rossii (2019). [Elektronnyj resurs]. Rezhim dostupa: https://infraoneresearch.ru/index id/2019, svobodnyj. - Zagl. s ekrana.

6. Kvon G. M. Régional'nye aspekty razvitiya investicionnogo potenciala ural'skogo makroregiona // Regional'nye problemy preobrazovaniya ekonomiki. - 2019. - № 9 (107). - S. 51-60.

7. Koncepciya organizacii $v$ Rossii metodologicheskoj sistemy po razvitiyu zelenyh finansovyh instrumentov $i$ proektov otvetstvennogo investirovaniya. [Elektronnyj resurs]. Rezhim dostupa: https://cbr.ru/Content/ Document/File/84163/press_04102019.pdf, svobodnyj. - Zagl. s ekrana.

8. Leochi P. Kachestvo zhizñi i ustojchivoe razvitie // Ekonomicheskie nauki. - 2012. - № 5(90). - S. 41-45.

9. Makkonnell, Kempbell R. Ekonomiks [Tekst]: principy, problemy i politika: [v 2 t.: per. s angl. 11-go izd.] / Kempbell R. Makkonell, Stenli L. Bryu. - Moskva: Respublika, 1993. - 27 sm. - T. 2. - 1993. - 400 s.: il. 
10. Osobennosti razvitiya chelovecheskogo kapitala v subëktah Rossijskoj Federacii. Analiticheskij centr pri Pravitel'stve Rossijskoj Federacii / 11.06.2019, Moskva. [Elektronnyj resurs]. Rezhim dostupa: https:// ac.gov.ru/files/content/22461/3-grigorev-pdf.pdf, svobodnyj. - Zagl. s ekrana.

11. Oficial'naya statistika. [Elektronnyj resurs]. Rezhim dostupa: https://www.gks.ru/investment nonfinancial, svobodnyj. - Zagl. s ekrana.

12. Popov E. V., Semyachkov K. A. Metodologiya ocenki social'nogo razvitiya regionov // Problemy razvitiya territorii. - 2018. - № 6 (98). -S. 119-130. DOI: 10.15838/ptd.2018.6.98.8 Popov E. V., Semyachkov K. A Method to Evaluate Social Development of Regions. Problems of Territory's development, 2018. No. 6 (98). P. 119-130.

13. Rezolyuciya General'noj Assambleej OON «Preobrazovanie nashego mira: Povestka dnya $v$ oblasti ustojchivogo razvitiva na period do 2030 goda». Prinyata 25 sentyabrya 2015 godal Rezolyuciya, prinyataya General'noj Assambleej. [Elektronnyj resurs]. Rezhim dostupa: https://undocs.org/ru/A/RES/70/1, svobodnyj. Zagl. s ekrana.

14. Rejting stran mira po urovnyu social'nogo progressa. [Elektronnyj resurs]. Rezhim dostupa: https:// www.socialprogress.org/?tab $=2 \&$ code $=N O R$, http://www.socialprogressimperative.org, svobodnyj. - Zagl. $s$ ekrana.

15.Ryzhakov E. D. Metodologiya formirovaniya sistemy infrastrukturnogo obespecheniya predprinimatel'skoj deyatel'nosti v regionah Rossii // Ekonomicheskie nauki. - 2012. - № 96. - S. 74-77.

16. Sajt «Associacii impakt-investorov». [Elektronnyj resurs]. Rezhim dostupa: http://impact-investor.org/, svobodnyj. - Zagl. s ekrana.

17. Sajt «Novyj biznes: social'noe predprinimatel'stvo». [Elektronnyj resurs]. Rezhim dostupa: http://nbforum.ru/useful/social_investing/10-factov-o-preobrazueshem-investirovanii, svobodnyj. - Zagl. s ekrana.

18.Strategiva prostranstvennogo razvitiva Rossijskoj Federacii na period do 2025 goda (2019), utverzhdena rasporyazheniem Pravitel'stva RF 13 fevralya 2019 g. № 207-r. [Elektronnyj resurs]. Rezhim dostupa: http:// static.government.ru/media/files/UVAlqUtT08o60RktoOXl22JjAe7irNxc.pdf, svobodnyj. - Zagl. s ekrana.

19. Timonina I. L. Gosudarstvenno-chastnoe partnerstvo $i$ «preobrazuyushchie» investicii v sfere social'noj infrastruktury: opyt YAponii / I. L. Timonina // Vostok. Afro-aziatskie obshchestva: istoriya i sovremennost'. 2016. - № 1. - S.143-159

20. YUdenko M. N., Mihajlov. M. V. Ekonomicheskaya sushchnost' infrastruktury $i$ ee osobennosti $v$ stroitel'stve // Vestnik Rossijskogo universiteta druzhby narodov. Seriya: Ekonomika. - 2013. - № 1. - S. 123130 .

21. K. Land. "Social Indicators», in "Encyclopedia of Sociology», MacRae, 1992, pag. 1844-1850; Revised Edition by E.F. Borgatta and R. V. Montgomery, "Encyclopedia of Sociology», Mcmillan, New York, 2000. W. Ogburn, "Recent Social Trends in the United States», pubblicato nel.

22. Overview Human Development Report 2019. Beyond income, beyond averages, beyond today: Inequalities in human development in the 21st century// Published for the United Nations Development Programme (UNDP). [An electronic resource]. Access mode: https://nonews.co/wp-content/uploads/2019/12/hdr2019.pdf, free. Heading from the screen.

23. Rosenstein-Rodan Notes on the Theory of the Big Push // Economic Development for Latin America/eds Ellis. - 1961.

24. Rosenstein-Rodan. Problems of Industrialisation of Eastern and South-Eastern Europe // The Economic Journal. Vol. 53. No. 210/211. - 1943.

25. Schnessler K. F., Fisher G. A. Quality of Life Research and Sociology // Annual Review of Sociology.1985. Vol. 11. R. 129-149. 